\title{
The Generalized Mandelbrot-Julia Set Form a Class of Complex Cosine Map
}

\author{
Poonam Negi \\ Research Scholar \\ Computer Science \& Engg. \\ Department \\ G. B. Pant Engg. College, \\ Pauri Garhwal (India)
}

\author{
Yashwant S. Chauhan \\ Asst.Professor \\ Computer Science \& Engg. \\ Department \\ G. B. Pant Engg. College, \\ Pauri Garhwal (India)
}

\author{
Priti Dimri \\ Asso.Professor \\ Computer Science \& Engg. \\ Department \\ G. B. Pant Engg. College, \\ Pauri Garhwal (India)
}

\begin{abstract}
The dynamics of transcendental function is one of emerging and interesting field of research nowadays. In this paper we have constructed a series of generalized Mandelbrot and Julia set from cosine function using Agarwal iteration.
\end{abstract}

\section{Keywords}

Agarwal Iteration, Complex Dynamics, Fixed Point, Julia set, Mandelbrot Set.

\section{INTRODUCTION}

In recent years there have been many papers dealing with the family of relational maps $z \leftarrow \cos \left(z^{n}+c\right), f(z)=1 / 2\left(e^{i z}+e^{-i z}\right)$. We have generated the fractal structure of the generalized Mandelbrot set and Julia set from three different cosine functions. Escape criteria of polynomials are used to generate Mandelbrot Sets and Julia Sets form Eq. (2). For Eq. (1) and Eq. (3) we have used Devaney's escape criterion[10].

$$
\begin{aligned}
& z \leftarrow c \cos z^{n}, n=1,2,3, \ldots \ldots ., c \in C \\
& z \leftarrow \cos z^{n}+c, c \in C, n=1,2,3, \ldots \ldots \ldots \\
& z \leftarrow \cos \left(z^{n}+c\right), c \in C, n=1,2,3, \ldots \ldots \ldots
\end{aligned}
$$

\section{PRELIMINARIES}

Let $(\mathrm{E}, \mathrm{d})$ be a complete metric space, $\mathrm{T}$ be a self map of E. Suppose that $F_{T}=\left\{p \in E\right.$ such that $\left.T_{p}=p\right\}$ is the set of fixed points of $T$ in $E$. In metric space we have several iterative processes that have been defined by many researchers to approximate the fixed points of different operators. One of them is following:

Let $\left\{x_{n}\right\}_{n=0}^{\infty} \subset E$ be the sequence generated by an iteration procedure involving the operator $\mathrm{T}$, that is, $x_{n+1}=f\left(T, x_{n}\right)$ $\mathrm{n}=0,1,2$.

where $x_{0} \in E$, be the initial approximation and $\mathrm{f}$ is some function. If $f_{i}(x)=x$, then point $\mathrm{x}$ is named the fixed point of $f_{i}$. If there is a smallest positive $p$ which satisfies $f^{p}(x)=x$, then $x$ is called a periodic point with period $p$. If $\mid\left(f^{p}\right) \dot{x}(\triangleleft \mid$, then $x$ is called a attracting fixed point. The point $x$ is a repelling fixed point if $\left|\left(f^{p}\right)^{\prime}(x)\right|>1$.

\subsection{Agarwal iteration [1]}

In 2007 Agarwal et al defines the iterative process as

$\mathrm{x}_{n+1}=(1-s) T x_{n}+s T y_{n}$

$y_{n}=\left(1-s^{\prime}\right) x_{n}+s^{\prime} T y_{n}$

Where $\{s\}$ and $\left\{s^{\prime}\right\}$ are the sequence of positive numbers in $[0,1]$ satisfying $\sum_{k=0}^{\infty} s_{k}=\infty$.

\subsection{Mandelbrot set $[7,10]$}

In 1980 Benoit Mandelbrot, the father of fractal geometry, discovered a fractal later to be known as the Mandelbrot Set .The Mandelbrot set $\mathrm{M}$ for the quadratic $Q_{c}(z)=z^{2}+c$, is defined as the collection of all $c \in C$ for which the orbit of the point 0 is bounded, that is $M=\left\{c \in C:\left\{Q_{c}{ }^{n}(0)\right\} ; n=0,1,2 \ldots \ldots . . . i\right.$ isbounded $\} . \quad$ An equivalent formulation is $M=\left\{c \in C:\left\{Q_{c}^{n}(0)\right\}\right.$ does not tends to $\infty$ as $n \rightarrow \infty$. We choose the initial point 0 , as 0 is the only critical point of $Q_{c}$.

\subsection{Julia set}

French mathematician Gaston Julia [2] and [8,9] investigated the iteration process of a complex function intensively, and attained the Julia set, a very important and useful concept. At present Julia sets has been applied widely in computer graphics, biology, Engineering and other branches of mathematical sciences.

Consider the complex-valued quadratic function $z_{n+1}=z^{n}+c, c \in C$, where $\mathrm{C}$ be the set of complex numbers and $\mathrm{n}$ is the iteration number. The Julia set for parameter $\mathrm{c}$ is defined as the boundary between those of $z_{0}$ that remain bounded after repeated iterations and those escape to infinity. The Julia set on the real axis are reflection symmetric, while those with complex parameter show rotation symmetry with an exception to $c=(0,0)$, see Rani and Kumar [6].

\section{GENERATING THE FRACTALS}

Fractals have been generated from $z \rightarrow\left(z^{n}+c\right), n \geq 2$ using escape-time techniques, for example by Gujar etal.[4, 5] and Glynn [3]. We have used in this paper escape time criteria of Agarwal iterates for second and third function. 


\subsection{Escape Criterion for Quadratics}

Suppose that $|\mathrm{z}|>\max \left\{|\mathrm{c}|, 2 / \mathrm{s}, 2 / s^{\prime}\right\}$, then $z_{n}\left|>(1+\lambda)^{n}\right| z \mid$ and $\left|z_{n}\right| \rightarrow \infty$ as $n \rightarrow \infty$. So, $\quad|z| \geq|c|$ and $|z|>2 / s$ as well as $|z|>2 / s^{\prime}$ shows the escape criteria for quadratics.

\subsection{Escape Criterion for Cubics}

\section{Suppose}

$|z|>\max \left\{|b|,(a+2 / s)^{1 / 2},\left(a+2 / s^{\prime}\right)^{1 / 2}\right\}$ then $\left|z_{n}\right| \rightarrow \infty$ as $n \rightarrow \infty$. This gives the escape criterion for cubic polynomials.

\subsection{General Escape Criterion}

Consider $|z|>\max \left\{|c|,(a+2 / s)^{1 / n},\left(a+2 / s^{\prime}\right)^{1 / n}\right\}$, then $\left|z_{n}\right| \rightarrow \infty$ as $n \rightarrow \infty$ is the escape criterion.

Based on the Devaney's escape criterion[10], we choose the escape time limit $|\operatorname{imag}(z)|>50$,otherwise a special denotation will be given. If $z=x+i y$, then

$$
\begin{aligned}
\cos z=1 / 2\left(e^{i z}+e^{-i z}\right) \\
|\cos z|=1 / 2\left|e^{i z}+e^{-i z}\right| \\
=1 / 2\left|e^{-y+i x}+e^{y-i x}\right| \\
=1 / 2\left|e^{-y} e^{i x}+e^{y} e^{-i x}\right| \\
=1 / 2\left(\left|e^{-y}\left\|e^{i x}|+| e^{y}\right\| e^{-i x}\right|\right) \\
=1 / 2\left(e^{-y}+e^{-y}\right) .
\end{aligned}
$$

Thus if imagz $<-50$, the modulus of the image of $z$ is quite large.

\section{ANALYSIS}

In this section we have presented the generalized Julia set of cosine function using Agarwal iterates. Further we have also presented the convergence of cosine function for different values of $s, s^{\prime}$ and $c$.

\subsection{For Eq.1}

For $z_{0}=(-1.25,0.0), \mathrm{n}=1, \mathrm{~s}=1.0$ and $\mathrm{s}^{\prime}=0.0$, we observe that the value for $F(z)$ converses to a fixed point i.e. 0.010 , see Fig1.1. On increasing the value to $z_{0}=(-2.4625,0.25), \mathrm{n}=1$, $\mathrm{s}=0.8$ and $\mathrm{s}^{\prime}=0.2$ we obtain fixed point as 0.2798 see Fig 1.2 . At $z_{0}=(1.6375,0.275), \mathrm{n}=1, \mathrm{~s}=0.6$ and $\mathrm{s}^{\prime}=0.1$, fixed point is 0.04595 see Fig 1.3. At $z_{0}=(3.275,0.0125), \mathrm{n}=1, \mathrm{~s}=0.4$ and $s^{\prime}=0.4$, fixed point is 0.06386 see Fig 1.4. At $z_{0}=(0.4625,0.5)$, $\mathrm{n}=2, \mathrm{~s}=0.4$ and $\mathrm{s}^{\prime}=0.4$, fixed point is 0.6399 see Fig 1.5 . At $z_{0}=$ $(-3.0125,-0.025), n=3, s=0.2$ and $s^{\prime}=0.5$, fixed point is 0.082 see Fig 1.6.

\subsection{For Eq.2}

For $z_{0}=(1.16875,-0.0125), \mathrm{n}=2, \mathrm{~s}=0.5$ and $\mathrm{s}^{\prime}=0.25$, we observe that the value for $F(z)$ converses to a fixed point i.e. 0.55274 see Fig2.1. At $z_{0}=(0.60625,-0.0875), n=3, \quad s=0.4$ and $s^{\prime}=0.2$,fixed point is 0.6728 see Fig2.2. At $z_{0}=(0.40625$, $0.20625), n=4, s=0.1$ and $s^{\prime}=0.3$, we observe that the value for $F(z)$ converges to two fixed points i.e. $0.6090,0.9919$ see Fig2.3.At $z_{0}=(-0.06388063243, \quad 0.01372904992) \quad, \mathrm{n}=4$, $\mathrm{s}=0.1$ and $\mathrm{s}^{\prime}=0.3$. we observe that the value for $F(z)$ converges to two fixed points i.e. 0.6090, 0.9919 see Fig 2.4.

\subsection{For Eq.3}

For $z_{0}=(1.925,0.025), \mathrm{n}=2, \mathrm{~s}=0.5$ and $\mathrm{s}^{\prime}=0.25$, we observe that the value for $F(z)$ converses to a fixed point i.e. 0.5119 see Fig3.1. For $z_{0}=(0.51875,0.525), \mathrm{n}=3, \mathrm{~s}=0.4$ and $\mathrm{s}^{\prime}=0.2$ value of fixed point is 0.6058 see Fig3.2. For $z_{0}=(-0.4125,-0.65), n=4$ $\mathrm{s}=0.1$ and $\mathrm{s}^{\prime}=0.1$ we obtain the fixed point 0.7969 see Fig3.3. For $z_{0}=(-0.4125,-0.65), \mathrm{n}=4, \mathrm{~s}=0.2$ and $\mathrm{s}^{\prime}=0.5$ we obtain the fixed point 0.7968 see Fig3.4.

\section{ITERATED IMAGES}

\subsection{Fractal growth of the generalized Mandelbrot set of eq.1}

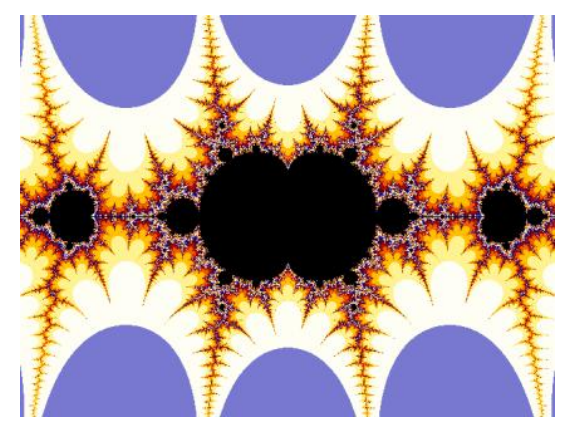

Fig1 for $s=1, s^{\prime}=0, n=1$

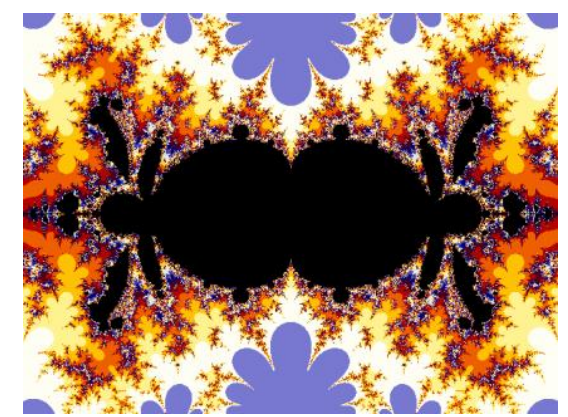

Fig2 for $s^{\prime}=0.8, s^{\prime}=0.2, n=1$

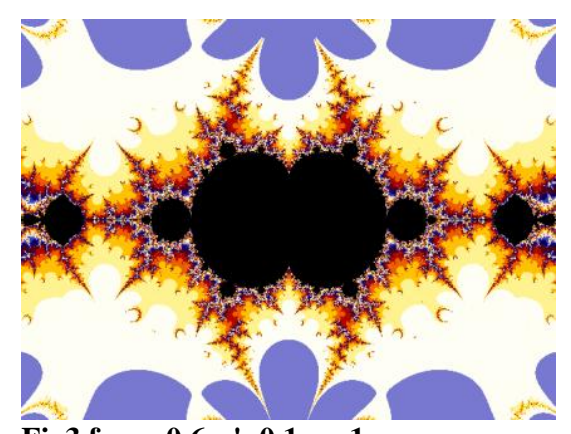

Fig3 for $s^{=0.6}, s^{\prime}=0.1, n=1$ 
Fig4 for $s^{\prime}=0.4, s^{\prime}=0.4, n=1$
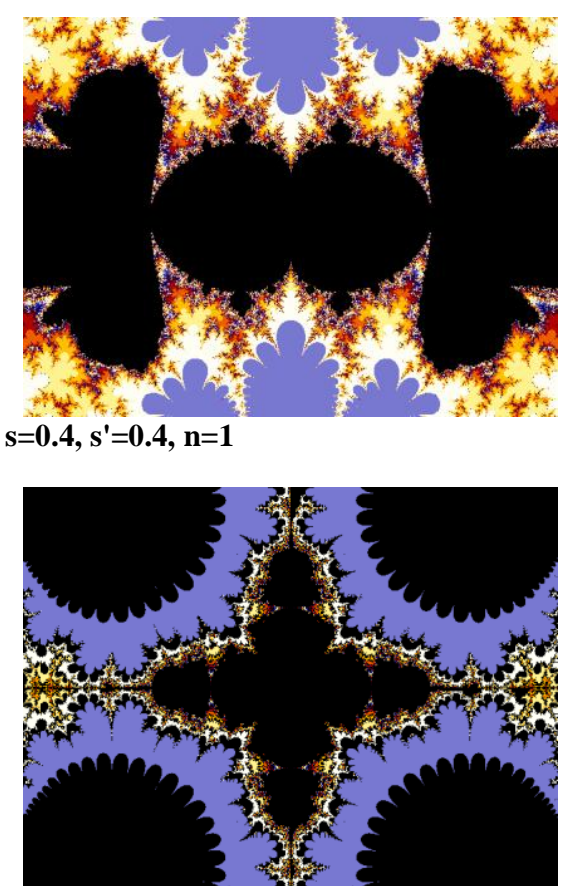

Fig5 for $s=0.5, s^{\prime}=0.25, n=2$

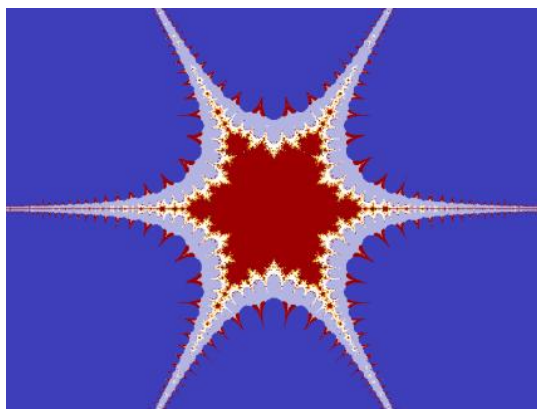

Fig6 for $\mathrm{s}=0.4, \mathrm{~s}^{\prime}=\mathbf{0 . 0}, \mathrm{n}=3$

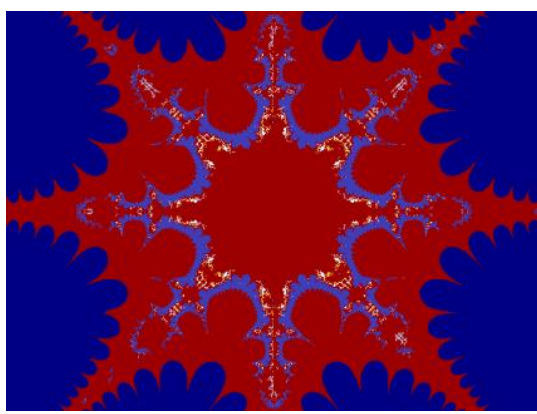

Fig7 for $s=0.6, s^{\prime}=0.5, n=4$

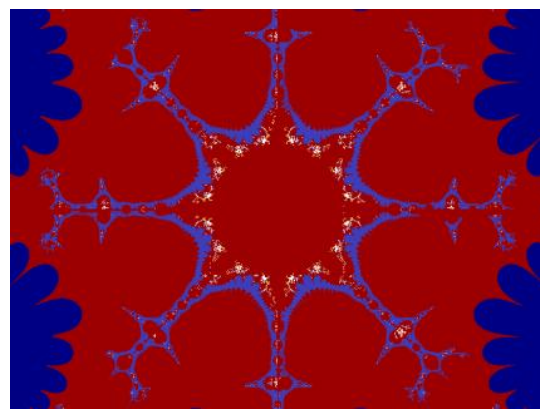

Fig8 for $\mathrm{s}=0.2, \mathrm{~s}^{\prime}=0.4, \mathrm{n}=4$

\subsection{Fractal growth of the Generalized} Mandelbrot Set of eq.2

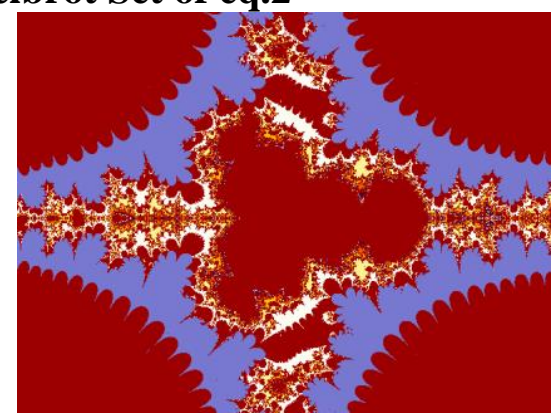

Fig1 for $s=0.5, s^{\prime}=0.2, n=2$

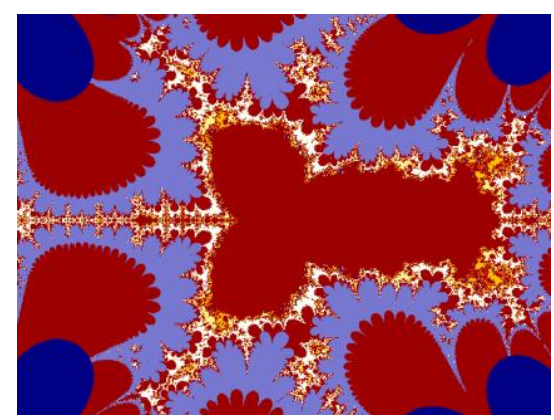

Fig2 for $s=0.6, s^{\prime}=0.5, n=2$

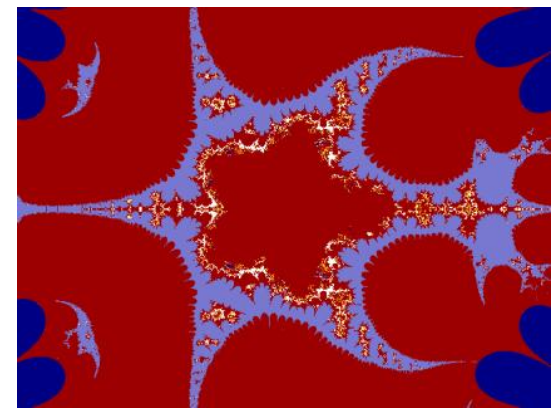

Fig3 for $s=0.4, s^{\prime}=0.4, n=3$

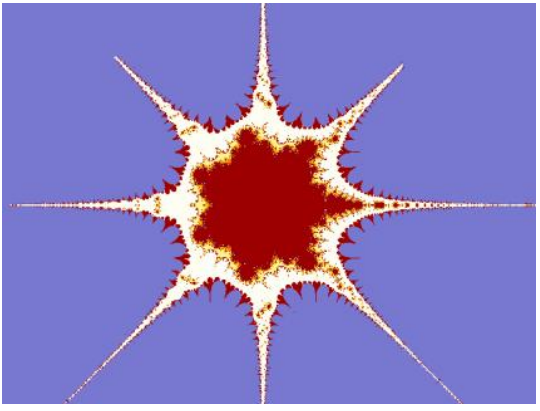

Fig4 for $s=0.6, s^{\prime}=0.0, n=4$ 
5.3 Fractal growth of the Generalized Mandelbrot Set of eq.3

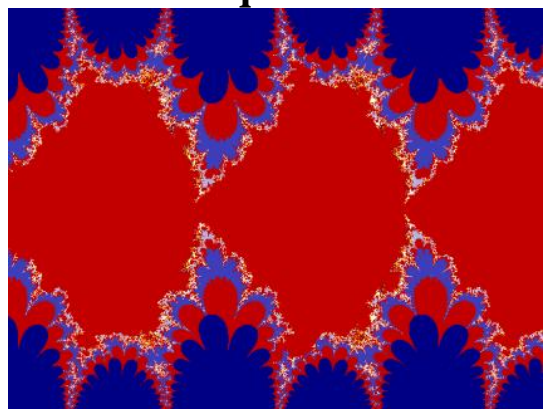

Fig1 for $\mathrm{s}=0.7, \mathrm{~s}^{\prime}=0.5, \mathrm{n}=2$

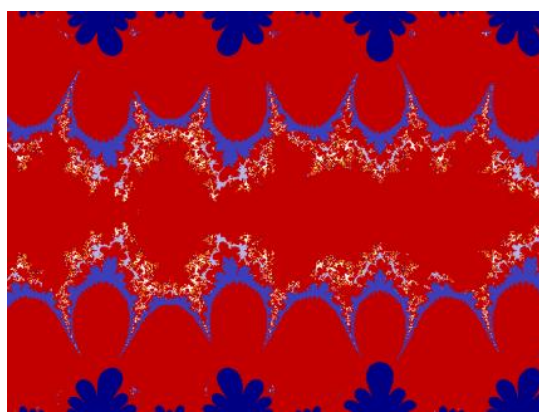

Fig2 for $s=0.4, s^{\prime}=0.2, n=3$

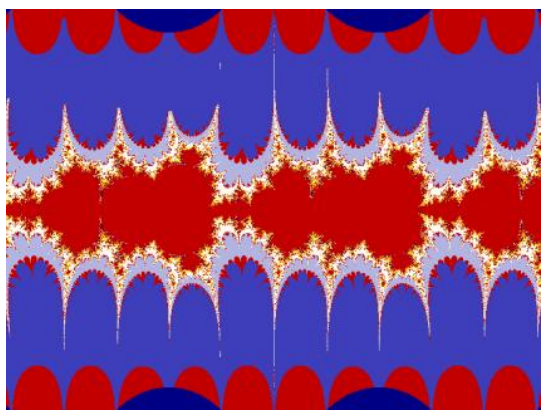

Fig3 for $s=0.2, s^{\prime}=0.0, n=4$

5.4 Fractal growth of the Generalized Julia Set of eq.1

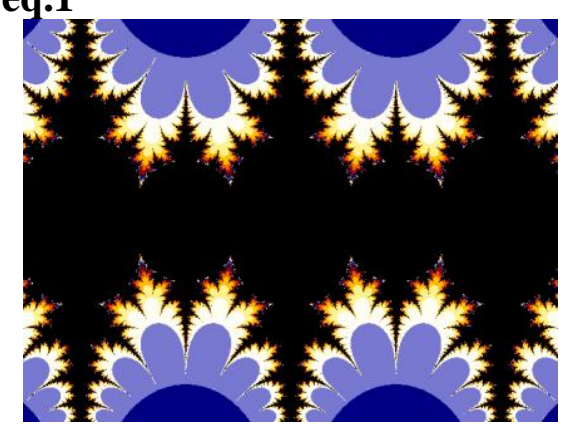

Fig1 for $s^{\prime}=1, s^{\prime}=0, n=1, c=-1.25+0 i$

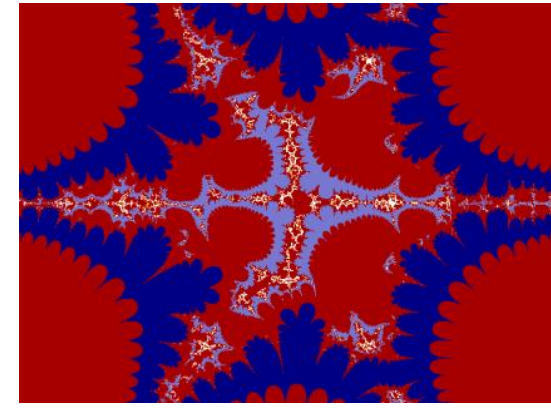

Fig2 for $s=0.2, s^{\prime}=0.5, n=3, c=-3.0125-0.025 i$

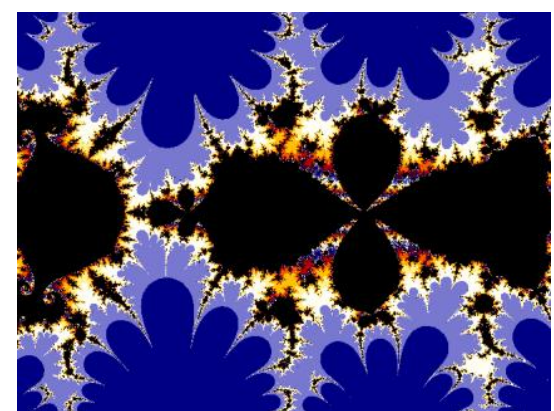

Fig3 for $s=0.4, s^{\prime}=0.4, n=1, c=3.275+0.0125 i$

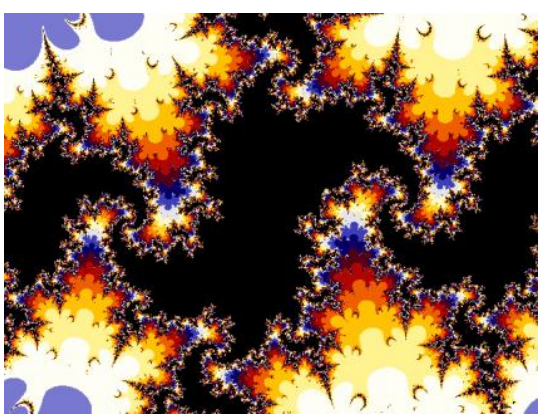

Fig4 for $s=0.6, s^{\prime}=0.1, n=1, c=1.6375+0.275 i$

5.5 Fractal growth of the Generalized Julia Set of eq.2

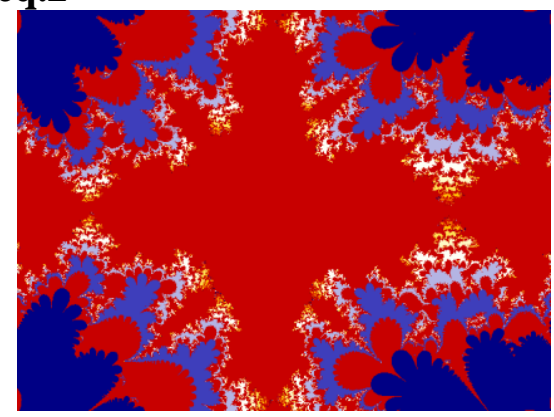

Fig1 for $s=0.5, s^{\prime}=0.25, n=2, c=1.16875-0.0125 i$ 


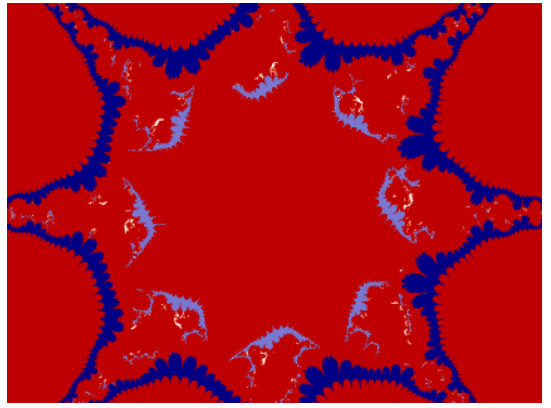

Fig2 for $\mathrm{s}^{=0.1}, \mathrm{~s}^{\prime}=0.3, \mathrm{n}=4, \mathrm{c}=$ $0.06388063243+0.01372904992 i$

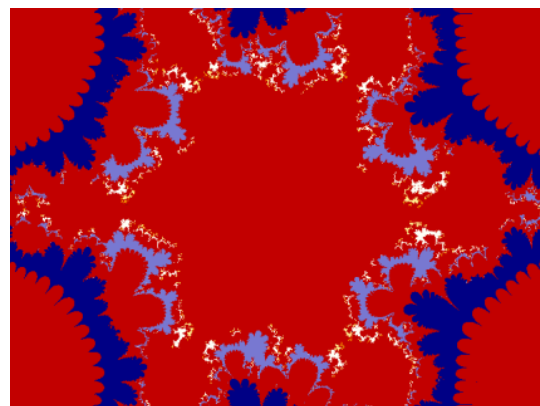

Fig3 for $\mathrm{s}=0.4, \mathrm{~s}^{\prime}=0.2, \mathrm{n}=3, \mathrm{c}=\mathbf{0 . 6 0 6 2 5 - 0 . 0 8 7 5 i}$

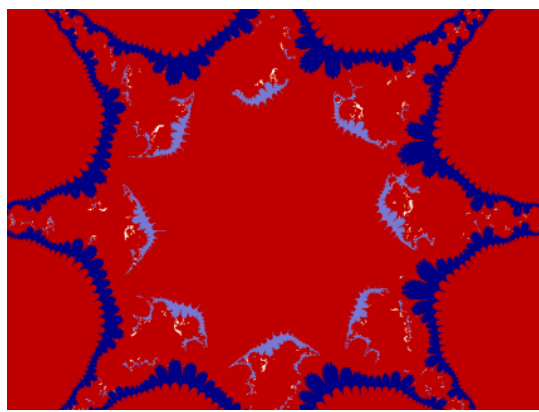

Fig4 for $s^{=0.1}, s^{\prime}=0.3, n=4, c=0.4625+0.5 i$

\subsection{Fractal growth of the Generalized Julia} Set of eq.3

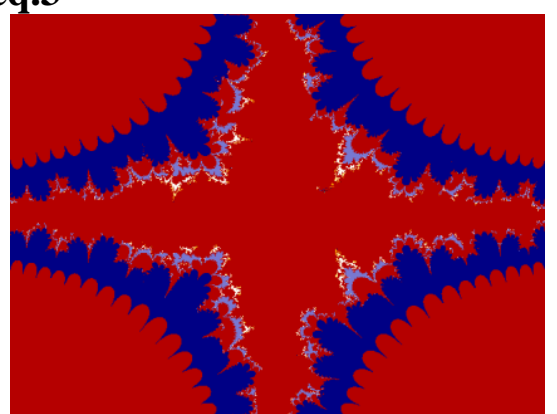

Fig1 for $s=0.5, s^{\prime}=0.25, n=2, c=1.925+0.025 i$

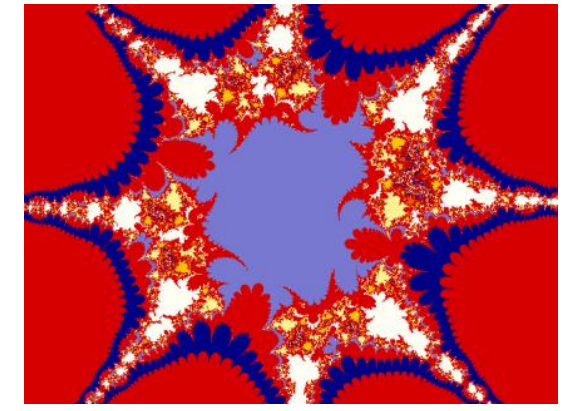

Fig2 for $s=0.2, s^{\prime}=0.5, n=4, c=-0.4125-0.65 i$

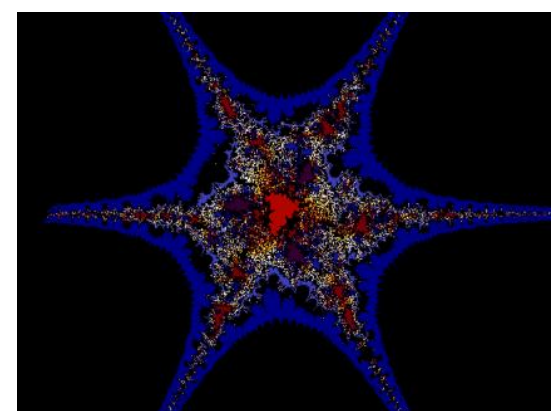

Fig3 for $\mathrm{s}^{=0.4}, \mathrm{~s}^{\prime}=0.2, \mathrm{n}=3, \mathrm{c}=\mathbf{0 . 5 1 8 7 5}+0.525 \mathrm{i}$

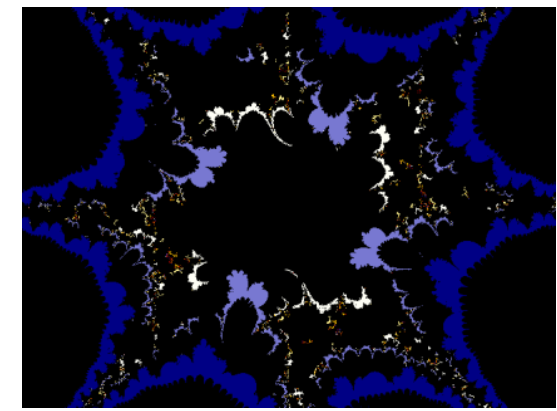

Fig4 for $s^{=0.1}, s^{\prime}=0.1, n=4, c=-0.4125-0.65 i$

\section{GRAPHS}

\subsection{For Eq. 1}

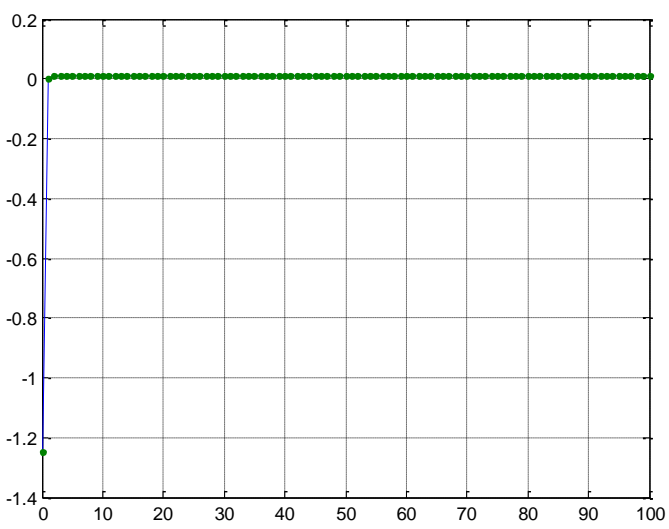

Fig 1.1: Orbit of $F(z)$ for $z 0=-1.25+0 i, n=1, s=1.0$ and $s^{\prime}=0.0$ 


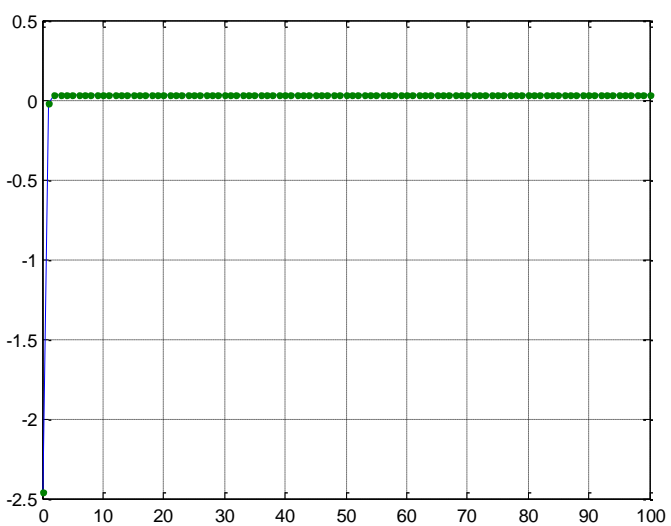

Fig 1.2: Orbit of $F(z)$ for $z 0=-2.4625+0.25 i, n=1, s=0.8$ and $\mathrm{s}^{\prime}=\mathbf{0 . 2}$

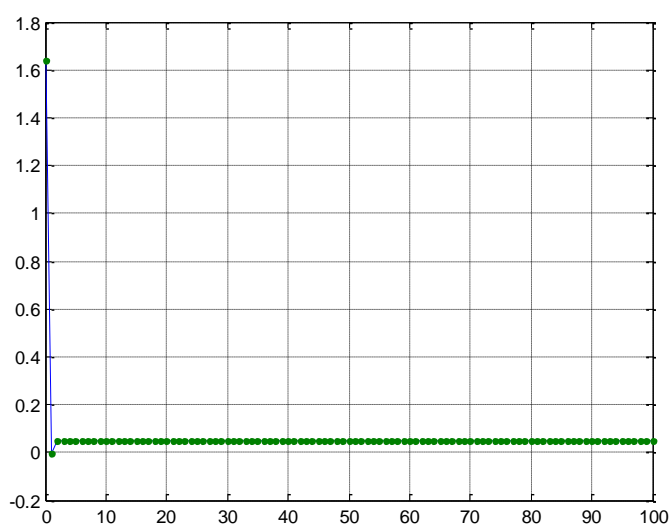

Fig 1.3: Orbit of $F(z)$ for $\mathrm{z} 0=1.6375+0.275 i, n=1, s=0.6$ and $s^{\prime}=0.1$

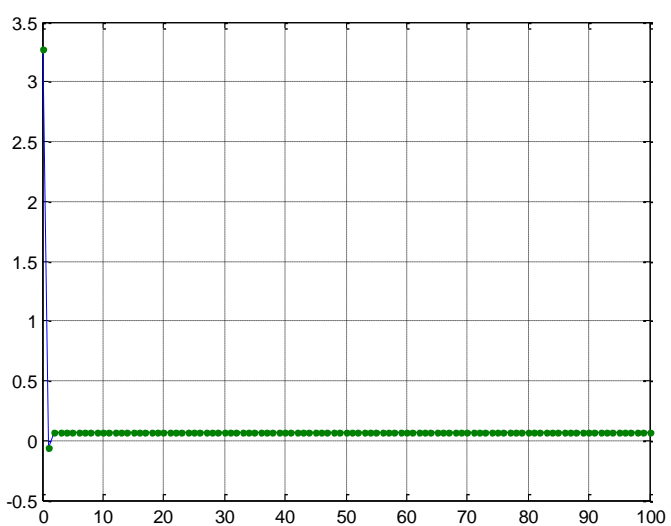

Fig 1.4: Orbit of $F(z)$ for $z 0=3.275+0.0125 i, n=1, s=0.4$ and $s^{\prime}=0.4$

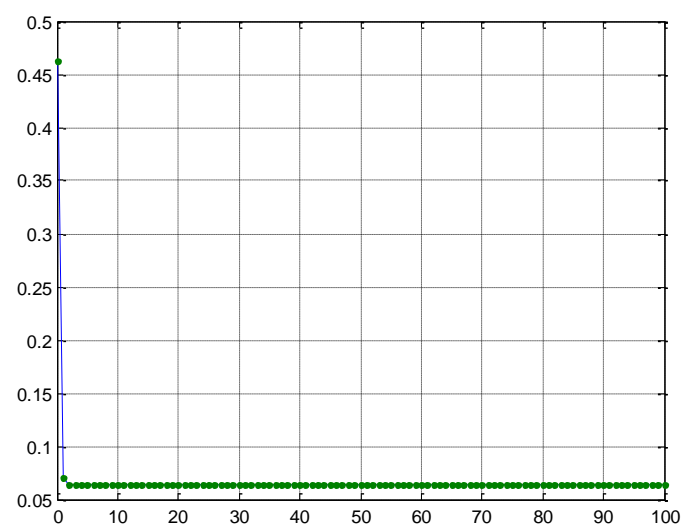

Fig 1.5: Orbit of $F(z)$ for $\mathrm{z0}=0.4625+0.5 i, n=2, s=0.4$ and $\mathrm{s}^{\prime}=\mathbf{0 . 4}$

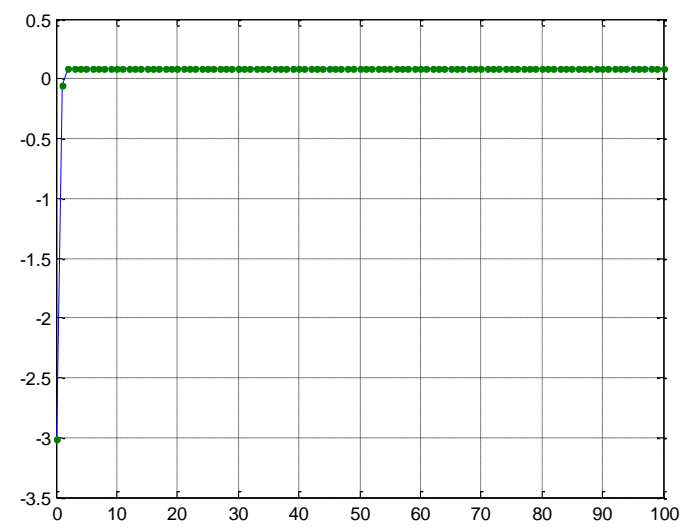

Fig 1.6: Orbit of $F(z)$ for $z 0=-3.0125-0.025 i, n=3, s=0.2$ and $s^{\prime}=0.5$

\subsection{For Eq.2:}

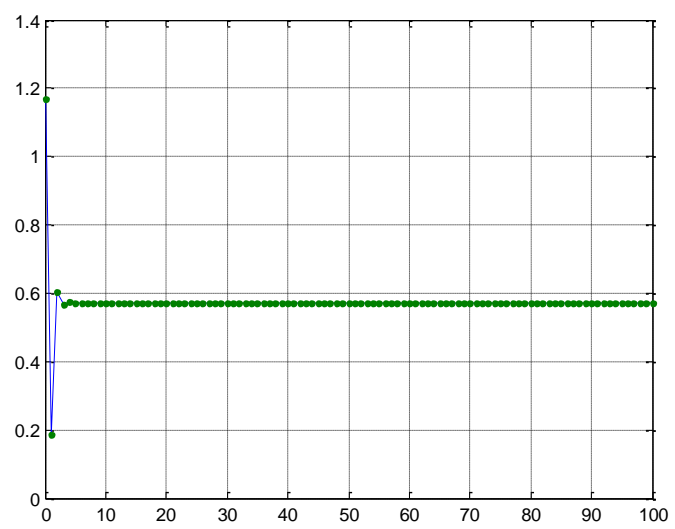

Fig 2.1: Orbit of $F(z)$ for $z 0=1.16875-0.0125 i, n=2, s=0.5$ and $\mathrm{s}^{\prime}=\mathbf{0 . 2 5}$ 


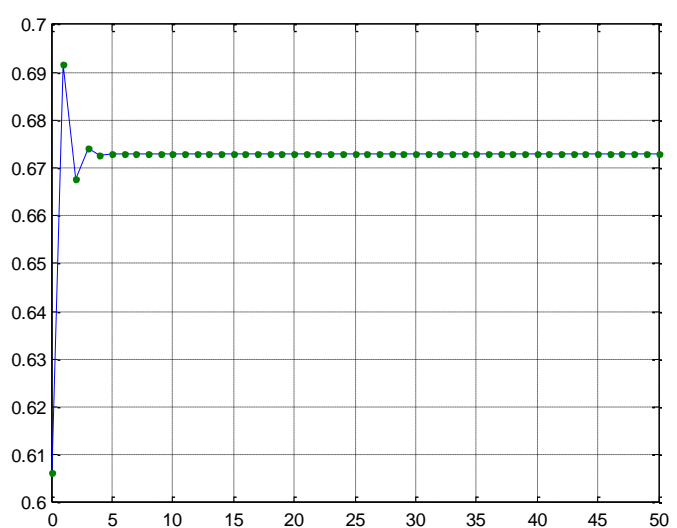

Fig 2.2: Orbit of $\mathrm{F}(\mathrm{z})$ for $\mathrm{z0}=0.60625-0.0875 \mathrm{i}, \mathrm{n}=3$, $\mathrm{s}=0.4 \mathrm{and}$ $\mathrm{s}^{\prime}=0.2$

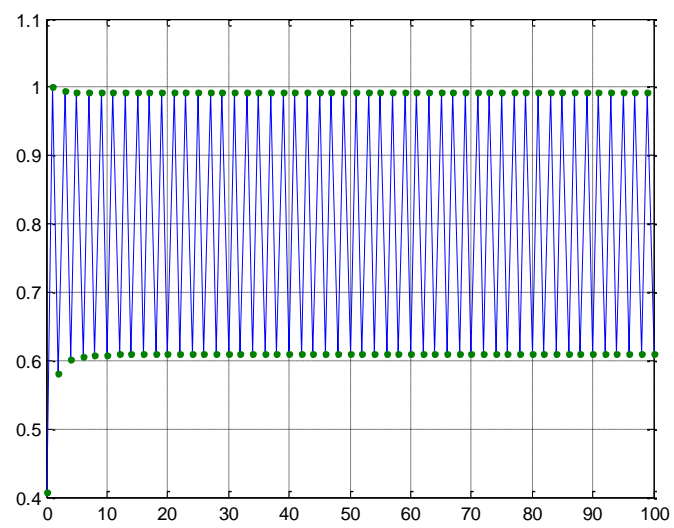

Fig 2.3: Orbit of $\mathrm{F}(\mathrm{z})$ for $\mathrm{z} 0=0.40625+0.20625 \mathrm{i}, \mathrm{n}=4$, $\mathrm{s}=0.1$ and $\mathrm{s}^{\prime}=0.3$

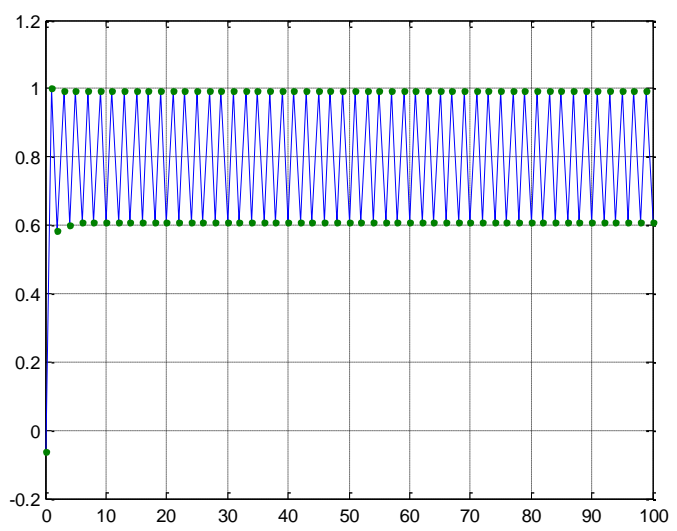

Fig 2.4: Orbit of $\mathrm{F}(\mathrm{z})$ for $\mathrm{z0}=$ -

$0.06388063243+0.01372904992 i, n=4, s=0.1$ and $s^{\prime}=0.3$

\subsection{For Eq.3:}

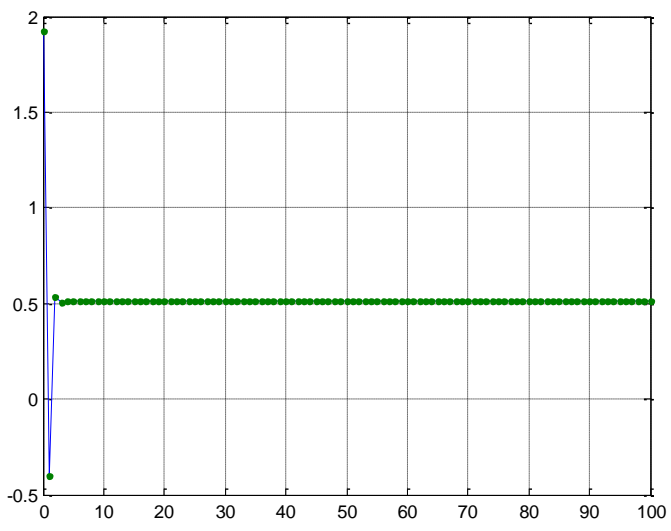

Fig 3.1: Orbit of $F(z)$ for $\mathrm{z} 0=1.925+0.025 i, n=2, s=0.5$ and $s^{\prime}=\mathbf{0 . 2 5}$

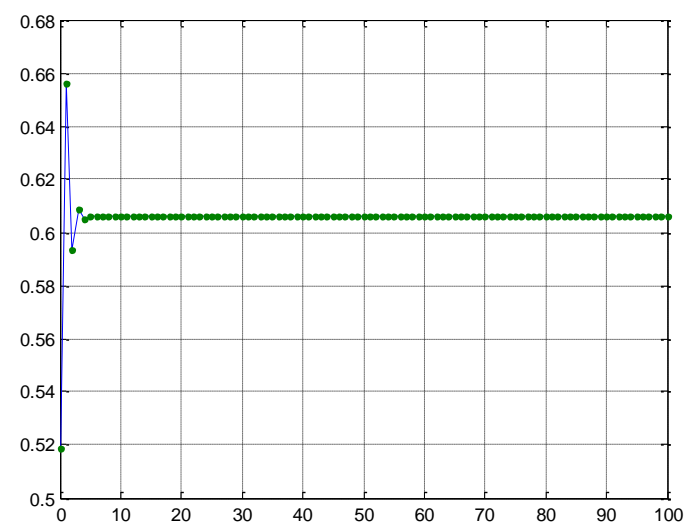

Fig 3.2: Orbit of $F(z)$ for $\mathrm{z} 0=0.51875+0.525 i, n=3, s=0.4$ and $\mathrm{s}^{\prime}=0.2$

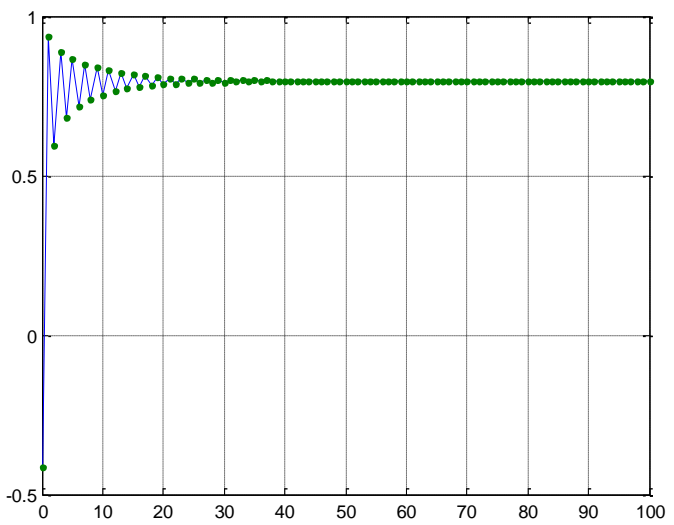

Fig 3.3: Orbit of $F(z)$ for $z 0=-0.4125-0.65 i, n=4 s=0.1$ and $s^{\prime}=0.1$ 


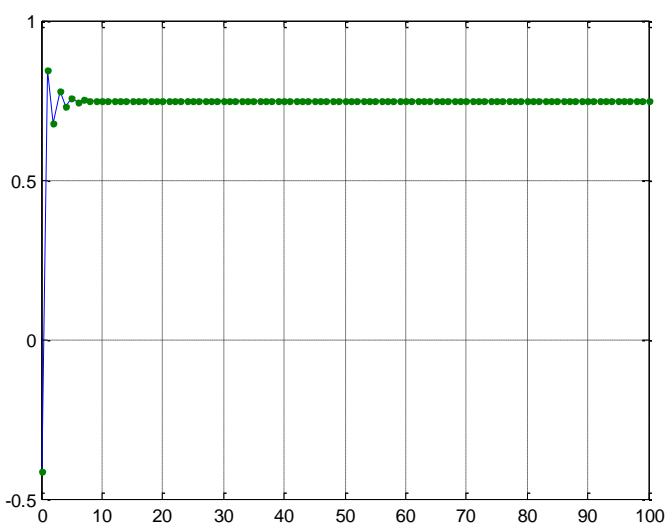

Fig 3.4: Orbit of $F(z)$ for $z 0=-0.4125-0.65 i, n=4, s=0.2$ and $s^{\prime}=0.5$

\section{CONCLUSION}

In this paper we have presented the dynamics and fixed point analysis of cosine map by using Agarwal iterates. Mandelbrot set of all three equations possesses $(2 n-1)$ bulbs while Julia sets possess $2 \mathrm{n}$ wings. The orbit of any point on hair tends to infinity under iteration. This geometry of hairs appears to be quite similar to that of exponential family and hence showed the property of transcendental function. On the other hand, Julia sets plane represented the region filled up of large number of escaping points.

\section{REFERENCES}

[1] Agarwal, R.P., O'Regan, D. and Sahu, D.R.: Iterative construction of fixed points of nearly symptotically nonexpansive mappings, Journal of Nonlinear and Convex Analysis 8(1) (2007), 61-79.

[2] Barnsley, Michael F., Fractals Everywhere. Academic Press, INC, New York, 1993.

[3] E. F. Glynn, "The Evolution of the Gingerbread Mann”, Computers and Graphics 15,4 (1991), 579 -582.

[4] U. G. Gujar and V. C. Bhavsar, "Fractals from $z=z^{\alpha}+c$ in the Complex c-Plane", Computers and Graphics 15, (1991), 441-449.

[5] U. G. Gujar, V. C. Bhavsar and N. Vangala, "Fractals from $z=z^{\alpha}+c$ in the Complex z-Plane", Computers and Graphics 16, 1 (1992), 45-49.

[6] Kumar, Manish. and Rani, Mamta., A new approach to superior Julia sets. J. nature. Phys. Sci, pp. 148-155, 2005.

[7] Mandelbrot B. B., "The Fractal Geometry of Nature, W. H. Freeman”, New York. ISBN 0-7167-1186-9.

[8] Peitgen, H. O., Jurgens, H. and Saupe, D., Chaos and Fractals. New frontiers of science, 1992.

[9] Peitgen, H.O., Jurgens, H. and Saupe, D., Chaos and Fractals: New Frontiers of Science. Springer-Verlag, New York, Inc, 2004.

[10] Robert L. Devaney, "A First Course in Chaotic Dynamical Systems: Theory and Experiment", Addison-Wesley, 1992. MR1202237. 